\title{
PERANCANGAN SISTEM INFORMASI PERSEDIAAN BARANG PADA BALAI BESAR PENGAWAS OBAT DAN MAKANAN
}

\author{
Rehulina Tarigan ${ }^{1}$, Budhy Raharjo $^{2}$ \\ ${ }^{1,2}$ Prodi Sistem Informasi Fakultas Ilmu Komputer Universitas Banten Jaya \\ Jl. Syeh Nawawi Al Bantani, Curug - Kota Serang - Indonesia \\ ${ }^{1}$ rtarigan@unbaja.ac.id \\ ²budiserang15@gmail.com
}

\begin{abstract}
Abstrak - Pada instansi pemerintah seperti Balai Besar Pengawas Obat dan Makanan (BBPOM) Serang, persediaan merupakan salah satu bagian yang penting untuk menjalankan kegiatan operasional dalam rangka pelayanan terhadap masyarakat. Persediaan merupakan aset dalam bentuk barang atau perlengkapan yang dimaksudkan untuk mendukung kegiatan operasional misalnya barang habis pakai dan barang tak habis pakai. Sistem informasi perseSdiaan yang ada di pemerintahan khususnya pada BBPOM Serang saat ini belum dilakukan secara optimal. Sistem tersebut belum mampu mengantisipasi kelebihan dan kekurangan barang persediaan yang diperlukan user atau pelanggan internal. Dengan kata lain, pada sistem belum ada inventory control yang dapat melakukan perhitungan berapa jumlah minimum, berapa jumlah maksimum, berapa safety stock untuk setiap barang persediaan. Untuk menjaga keberlangsungan pelayanan terhadap user di BBPOM Serang, diperlukan beberapa jenis barang tertentu dalam jumlah minimum tersedia di gudang, supaya jika sewaktu-waktu ada permintaan user yang bersifat urgent dapat langsung dipenuhi. Tetapi barang yang disimpan dalam persediaan juga jangan terlalu banyak, ada batas maksimumnya, agar biayanya tidak menjadi terlalu mahal. Selain itu, proses permintaan barang di BBPOM Serang menunjukkan adanya kendala yaitu pegawai (user) dalam melakukan permintaan barang tidak dapat mengetahui stok barang terkini secara realtime, sehingga harus menghubungi pengelola persediaan sebelum melakukan permintaan barang. Kendala ini mengakibatkan proses operasional dapat terhambat karena harus menunggu respon dari pihak pengelola persediaan. Untuk mengatasi masalah seperti yang diuraikan di atas, maka perlu dibangun dan dikembangkan suatu sistem informasi persediaan barang di BBPOM Serang. Metode yang dipergunakan untuk mengetahui jumlah maksimum, jumlah minimum dan safety stock suatu barang di gudang adalah metode Min-Max stock level. Metode pengumpulan data yang digunakan dalam penelitian ini adalah dengan cara studi literatur, observasi atau pengamatan secara langsung dan wawancara sehingga mendapatkan data-data yang akurat. Metodologi yang digunakan untuk perancangan dan pengembangan sistem adalah metode waterfall yang merupakan bagian dari System Development Life Cycle (SDLC). Sedangkan pemodelan proses bisnis menggunakan Data Flow Diagram (DFD) atau Data Alir Diagram (DAD). Aplikasi yang dibangun atau dikembangkan dapat memenuhi kebutuhan akan permintaan barang dengan cepat, di mana setiap pihak terkait dapat mengetahui stok secara realtime. Sistem tersebut juga diharapkan mampu melakukan inventory control dengan baik yaitu perhitungan atau pengendalian mengenai jumlah suatu persediaan dapat dihitung secara otomatis.
\end{abstract}

Kata Kunci : Aplikasi Persediaan, BBPOM Serang, Instansi Pemerintah, Min-Max Stock Level.

\section{PEndahuluan}

Pada instansi pemerintah seperti pada Balai Besar Pengawas Obat dan Makanan (BBPOM) Serang persediaan merupakan salah satu bagian yang penting untuk menjalankan kegiatan operasional dalam rangka pelayanan terhadap masyarakat. Menurut Herjanto (1999) persediaan adalah bahan atau barang yang disimpan yang akan digunakan untuk memenuhi tujuan tertentu, misalnya untuk proses produksi atau perakitan, untuk dijual kembali, dan untuk suku cadang dari suatu peralatan atau mesin. Persediaan dapat berupa bahan mentah (raw materials), bahan pembantu, barang dalam proses, barang jadi, ataupun suku cadang. Fungsi utama persediaan yaitu sebagai penyangga dan penghubung kegiatan perusahaan atau instansi pemerintah dalam kebijakan perawatan yang digunakan. Masalah perencanaan dan pengendalian persediaan merupakan salah satu hal yang paling penting yang harus dihadapi setiap perusahaan atau organisasi. Tanpa persediaan, perusahaan akan dihadapkan pada resiko bahwa perusahaan tidak dapat memenuhi permintaan pelanggan tepat waktu. Hal ini mungkin saja terjadi karena tidak selamanya barang-barang tersedia setiap saat, yang berarti bahwa perusahaan akan kehilangan kesempatan untuk memperoleh keuntungan yang seharusnya didapatkan (Fadhilah, Andreas, \& Zahedi, 2008).

Menurut Indrajit \& Djokopranoto (2003) untuk menjaga kelangsungan beroperasinya suatu pabrik atau fasilitas lain, diperlukan beberapa jenis material tertentu dalam jumlah 
minimum tersedia di gudang, supaya sewaktu-waktu ada yang rusak, dapat langsung diganti. Tetapi material yang disimpan dalam persediaan juga jangan terlalu banyak, harus memiliki batas maksimum agar biaya yang ditimbulkan tidak terlalu mahal. Inventory control sangat diperlukan, dimana harus ada pengendalian tingkat persediaan sedemikian rupa. Hal ini merupakan upaya sehingga setiap kali barang diperlukan, selalu tersedia dan harus menjaga agar tingkat persediaan dapat seminimal mungkin agar menghindari investasi berupa biaya penyediaan yang besar.

Bagaimana halnya dengan BBPOM Serang sebagai instansi pemerintah yang tugasnya adalah untuk melayani masyarakat sehingga obat atau makanan yang beredar di pasar aman untuk dikonsumsi oleh masyarakat? Walaupun BBPOM Serang bukan lembaga yang mencari profit seperti perusahaan manufacture atau pabrik pada umumnya, namun sistem persediaan sangat penting karena menyangkut keamanan dan keselamatan masyarakat terhadap obat dan makanan yang dikonsumsi. Jangan sampai persediaan untuk pengujian bahan obat atau makanan tidak tersedia di gudang padahal saat itu sedang beredar suatu bahan obat atau makanan yang mengandung zat berbahaya untuk kesehatan manusia. Dapat juga suatu obat atau makanan mengandung bahan yang tidak sesuai dengan komposisinya sehingga dapat mengancam kesehatan masyarakat. Pada saat yang bersamaan, bahan baku pembanding tidak tersedia di gudang BBPOM Serang sehingga pihak BBPOM Serang tidak dapat melakukan pemeriksaaan kandungan makanan dan obat tersebut dengan menggunakan bahan baku pembanding.

Hasil pengamatan awal terhadap proses permintaan barang di BBPOM Serang menunjukkan adanya kendala yaitu pelanggan internal atau pegawai dalam melakukan permintaan barang tidak dapat mengetahui secara langsung stok barang terkini, sehingga harus menghubungi pengelola persediaan sebelum melakukan permintaan barang. Pengelola persediaan juga tidak bisa secara realtime mengetahui barang apa saja yang sudah dilakukan pembelian oleh Pejabat Pembuat Komitmen (PPK) pada kantor BBPOM Serang. PPK atau Kepala Balai mengalami kesulitan terhadap analisa pengadaan barang atau pengendalian terhadap persediaan (inventory control) khususnya dalam menentukan jumlah minimum dan jumlah maksimum untuk suatu barang yang ada di gudang. Pada artikel ini akan dibahas semua variabel penting dalam melakukan inventory control sesuai dengan metode min-max stock level seperti: menentukan safety stock, persediaan minimum, persediaan maksimum, pemesanan kembali (reorder point).

Persediaan yang ada pada BBPOM Serang pada umumnya tidak terkait dengan bahan baku untuk diproduksi menjadi barang jadi seperti yang dilakukan oleh perusahaan manufaktur. Selain dari Alat Tulis Kantor (ATK) dan perlengkapan Kesehatan \& Keselamatan Kerja (K3), ada beberapa kategori barang persediaan utama di BBPOM Serang, seperti: a. Reagensia cair merupakan bahan kimia cair untuk melakukan pengujian terhadap obat dan makanan yang akan diuji terhadap bahan berbahaya. Misalnya Acetonitrile GR p.a, Cyclohexane GR p.a

b. Reagensi padat merupakan bahan kimia dalam bentuk padat untuk melakukan pengujian terhadap obat dan makanan. Misalnya Boric Acid (asam borat)

c. Media Micro merupakan bahan kimia untuk menguji apakah suatu obat atau makanan mengandung microba yang sesuai, misalnya pada air mineral merek tertentu ada microba tetapi tidak boleh melewati batas ambang tertentu. Contoh media micro adalah Aflatoksin B1

d. Baku Pembanding, untuk membandingkan bahan baku dari obat atau makanan, apakah bahan bakunya sesuai atau tidak. Misalnya terigu, apakah benar-benar mengandung terigu dan bukan sagon. Contoh baku pembanding adalah asam folat, asam mefemanat.

Berdasarkan uraian di atas, dapat diidentifikasikan beberapa permasalahan yang muncul dalam pengelolaan stok persedian di BBPOM Serang, di antaranya adalah:

a. Sering terjadi kekosongan stok persedian di gudang, sehingga terlambat dalam melakukan pelayanan.

b. Belum tersedia layanan informasi berbasis web, sehingga akses informasi stok persedian terbatas hanya pada pengelola persediaan dan tidak dapat diakses secara realtime.

c. Dalam melakukan pembelian, Pejabat Pembuat Komitmen (PPK) atau Kepala Balai mengalami kesulitan terhadap analisa pengadaan barang. Hal ini berkaitan dengan penentuan safety stock, jumlah minimum, jumlah maksimum dan reorder point suatu barang belum dapat dihitung secara tepat dan akurat.

Dalam penelitian ini, penulis merumuskan beberapa masalah yang dapat diselesaikan, di antaranya adalah:

a. Bagaimana cara supaya laporan dapat cepat didapatkan serta stok dapat dilihat secara realtime oleh pihak-pihak yang berkepentingan?

b. Bagaimana mempermudah dan mempercepat Pejabat Pembuat Komitmen (PPK) atau Kepala Balai dalam melakukan analisa pengadaan persedian?

Diharapkan dengan adanya sistem persediaan berbasis web, pengelola persediaan dapat dengan mudah dan cepat untuk melihat dan mengetahui data stok yang terkini pada aplikasi web. Data stok, khususnya stok di awal bulan dapat menjadikan dasar untuk menghitung batas minimal dan maksimal stok persediaan. Pada setiap akhir atau awal bulan dilakukan proses closing untuk dapat mengetahui berapa stok awal untuk bulan berikutnya. Dengan demikian, pengolah persediaan akan sangat terbantu dalam memenuhi permintaan persediaan dari pelanggan internal pada waktu dan jumlah yang tepat. Sehingga proses persediaan barang pada BBPOM Serang dapat lebih efektif dan efisien. Selain itu, sistem yaang akan dibangun juga dapat bermanfaat dalam mempermudah proses permintaan barang oleh masing-masing pihak pelanggan internal atau pegawai. Manfaat lain dari sistem 
yang akan dibangun adalah mempermudah proses pelaporan stok barang ke Pejabat Pembuat Komitmen (PPK) atau Kepala Balai.

\section{Metodologi Penelitian}

\section{A. Metode Pengumpulan Data}

Dalam membangun sistem informasi ini, penulis menggunakan metodologi untuk pengumpulan data sebagai berikut:

a. Pengamatan (Observasi), yaitu mengadakan peninjauan langsung terhadap kegiatan dan sistem yang berjalan sehingga penulis dapat memahami proses bisnis pengadaan serta pengendalian persediaan yang ada pada BBPOM Serang.

b. Wawancara (Interview), yaitu melakukan tanya jawab secara langsung dengan pihak-pihak yang mengetahui tentang permasalahan yang ada di BBPOM Serang. Dari wawancara, tim penulis dapat memperoleh sejumlah data dan informasi yang diperlukan. Selain itu, penulis juga memperoleh sejumlah bentuk laporan yang diperlukan baik oleh pengolah barang di gudang, user sebagai pihak yang melakukan permintaan serta Kepala Balai yang berkepentingan dalam melakukan inventory control.

c. Studi Pustaka, yaitu teknik mempelajari sejumlah teori yang ada mengenai terminologi atau istilah dan pengelolaan sistem informasi yang berhubungan dengan Sistem Persediaan dan inventory control atau pengendalian persediaan.

\section{B. Metode Pengembangan Sistem Informasi}

Adapun metodologi pengembangan sistem yang penulis gunakan adalah metode waterfall. Metode ini sudah digunakan secara luas untuk pengembangan aplikasi perangkat lunak dan merupakan model klasik dari rekayasa perangkat lunak yang banyak digunakan dalam berbagai macam proyek baik pemerintahan maupun perusahaan besar swasta lainnya. Metode ini sangat terstruktur, tertapi cenderung bersifat linier dan tidak fleksibel. Metode ini memerlukan pendekatan yang sistematis dan sekuensial di dalam pengembangan sistem perangkat lunak. Sommerville (2011:31) dalam bukunya mengungkapkan bahwa tahapan dari model waterfall meliputi aktifitas seperti pada gambar berikut:

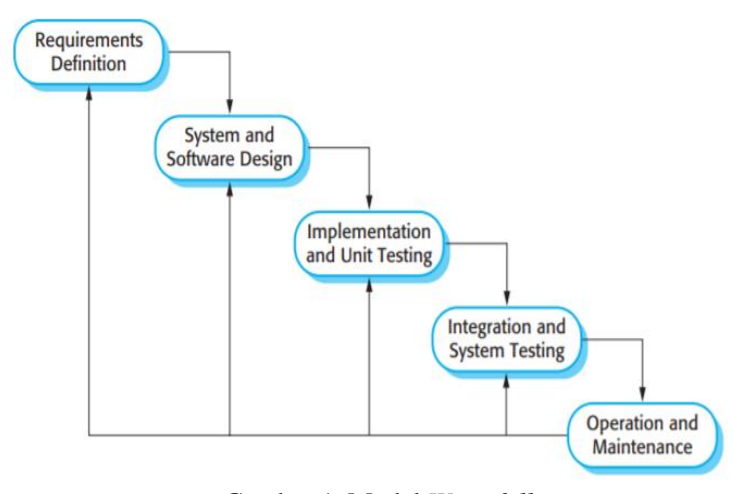

Gambar 1. Model Waterfall

Berdasarkan motodologi yang dikemukakan oleh Sommerville seperti gambar di atas, maka penulis melakukan tahapan untuk mengumpulkan semua persyaratan sistem sesuai dengan kebutuhan dari pengguna. Seperti yang sudah dijelaskan sebelumnya, maka tahapan pengumpulan data dilakukan dengan observasi dan wawancara langsung ke pengguna yang akan memakai sistem. Pada tahapan ini, penulis memperoleh gambaran proses bisnis yang ada di lapangan, memperoleh sejumlah data berdasarkan format beberapa laporan yang user gunakan selama ini. Setelah data dikumpulkan, lalu dianalisa bagaimana hubungan antara data yang satu dengan data yang lain, memperkirakan seperti apa screen atau antar muka yang bagus dan sesuai kebutuhan user.

Setelah tahap analisa, maka penulis dan tim akan melakukan perancangan basis data dengan menerapkan prinsip normalisasi sehingga semua tabel atau entitas yang dipergunakan sudah dalam bentuk normal. Normalisasi merupakan parameter digunakan untuk menghindarari duplikasi terhadap tabel dalam basis data. Pada saat normalisasi dilakukan juga proses mendekomposisikan sebuah tabel yang masih memiliki beberapa anomali atau ketidak wajaran sehingga menghasilkan tabel yang lebih sederhana dan struktur yang bagus. Tabel yang dihasilkan adalah sejumlah tabel yang tidak memiliki data redundancy dan memungkinkan user untuk melakukan insert, delete, dan update pada baris (record) tanpa menyebabkan inkonsistensi data (Triyono, 2011). Selain perancangan basis data, juga dilakukan perancangan antar muka dengan pengguna serta perancangan laporan-laporan yang secara otomatis dapat diperoleh dari sistem aplikasi yang akan dikembangkan. Penulis akan membahas dan menunjukkan hasil dari proses atau tahapan aktifitas pengembangan perangkat lunak pada bagian Hasil dan Pembahasan.

\section{Pemodelan Proses Bisnis}

Untuk mendapatkan spesifikasi perangkat lunak yang diharapkan sesuai dengan keinginan dan kebutuhan pengguna, tim peneliti melakukan pemodelan secara visual. Pemodelan visual adalah proses penggambaran informasi-informasi secara grafis dengan notasi-notasi baku yang telah disepakati sebelumnya (Nugroho, 2005:17). Untuk melakukan 
pemodelan proses bisnis yang ada pada sistem informasi persediaan di BBPOM Serang, maka penulis menggunakan Data Flow Diagram (DFD) yang meliputi diagram konteks dan diagram rinci pada level yang lebih detail. Data Flow Diagram (DFD) disebut juga dengan Diagram Arus Data (DAD). Defenisi Diagram Konteks (Context Diagram) berdasarkan situs online.visual-paradigm.com adalah diagram tertinggi dalam diagram aliran data (DFD) dan hanya berisi satu proses mewakili keseluruhan sistem, yang menetapkan konteks dan batasan sistem yang akan dimodelkan. Diagram ini akan mengidentifikasikan arus informasi antar sistem dan entitas eksternal (aktor).

DFD adalah suatu model logika data atau proses yang dibuat untuk menggambarkan dari mana asal data dan kemana tujuan data yang keluar dari sistem, di mana data disimpan, proses apa yang menghasilkan data tersebut, dan interaksi antara data yang tersimpan, dan bagaiman proses yang dikenakan pada data tersebut (Kristanto,2008). Salah satu manfaat DFD adalah memungkinkan penganalisis sistem memahami keterkaitan antara subsistem yang satu dengan subsistem yang lainnya pada sistem yang sedang digambarkan. Pemodelan dengan DFD dapat digunakan untuk mengkomunikasikan sistem kepada pengguna karena sistem digambarkan secara terstruktur (Kendall, 2003).

\section{Konsep Min-Max Stock Level}

Konsep persediaan minimum dan maksimum dapat dilakukan setiap waktu, dengan konsep titik pemesanan kembali atau reorder point. Menurut Murti, Karima Batennia dkk (2019), konsep persediaan maksimum dan minimum ditentukan dengan jumlah persediaan maksimum dan minimum. Jika persediaan sudah mencapai jumlah minimum maka segera dilakukan pembelian barang hingga jumlah barang dapat mencapai persediaan maksimum. Jika persediaan barang sudah mencapai persediaan maksimum maka pembelian dihentikan. Ketika barang dalam persediaan digunakan terus menerus, maka persediaan akan mencapai titik minimum lagi dan seterusnya. Konsep ini dikembangkan berdasarkan pemikiran bahwa untuk menjaga kelangsungan beroperasinya suatu perusahaan, instansi pemerintahan atau fasilitas lain, beberapa jenis barang tertentu dalam jumlah minimum sebaiknya tersedia di persediaan, supaya sewaktuwaktu dibutuhkan, dapat langsung digunakan. Akan tetapi barang yang disimpan tidak diperbolehkan terlalu banyak, sehingga terdapat nilai maksimumnya.

Menurut C. Yedida, and M. Ulkhaq (2017) bahwa dalam inventory control dengan menggunakan metode min-max stock meliputi beberapa tahapan yaitu:

a. Menentukan Persediaan Pengaman (Safety Stock). Safety Stock atau persediaan pengaman adalah persediaan ekstra yang perlu ditambah untuk menjaga sewaktu-waktu ada tambahan kebutuhan atau keterlambatan kedatangan barang. Formula Safety Stock $=($ Pemakaian maksimal - Rata-rata kebutuhan $)$ $\mathrm{x}$ Lead time. Lead time adalah waktu rata-rata yang dibutuhkan supplier untuk pengiriman barang.

b. Menentukan Persediaan Minimum (Minimum stock). Minimum Stock adalah jumlah pemakaian selama waktu pesanan pembelian yang dihitung dari perkalian antara waktu pesanan per periode dan pemakaian ratarata dalam satu bulan/minggu/hari ditambah dengan persediaan pengaman. Formula Minimum stock = (Rata-Rata Kebutuhan x Lead Time) + Safety Stock.

c. Menentukan Persediaan Maksimum (Maximum Inventory). Maximum Stock adalah jumlah maksimum yang diperbolehkan disimpan dalam persediaan. Formula Maximum stock $=2 \mathrm{x}$ (Rata-Rata Kebutuhan $\mathrm{x}$ Lead Time) + Safety Stock.

d. Jumlah yang perlu dipesan untuk pengisian persediaan kembali (reorder point). Formula untuk Reorder Point (Q) = Maksimum - Minimum.

Untuk melakukan perhitungan terhadap keempat variabel di atas dengan menggunakan metode min-max stock level, akan dibuat simulasi data dalam bentuk tabel. Tabel tersebut menjelaskan jumlah kebutuhan dan jumlah pemakaian suatu barang jenis reagensia padat Barium Chloride Dihydrate $(\mathrm{BaCl} 2)$ dalam periode satu tahun yaitu 2020. Pembelian dilakukan setiap bulan sehingga angka lead time adalah 1.

Tabel 1. Jumlah Kebutuhan dan Pemakaian BaCl2

\begin{tabular}{|c|c|c|c|c|}
\hline \multicolumn{5}{|c|}{ Tahun 2020} \\
\hline Peiode & $\begin{array}{l}\text { Nama } \\
\text { Bahan }\end{array}$ & $\begin{array}{c}\text { Jumlah } \\
\text { Kebutuhan } \\
\text { (Botol @1000 g) }\end{array}$ & $\begin{array}{c}\text { Jumlah } \\
\text { Pemakaian } \\
\text { (Botol @1000 g) }\end{array}$ & $\begin{array}{c}\text { Sisa } \\
\text { (Botol } \\
@ 1000 \mathrm{~g})\end{array}$ \\
\hline Januari & $\mathrm{BaCl} 2$ & 30 & 30 & 0 \\
\hline Pebruari & $\mathrm{BaCl} 2$ & 35 & 30 & 5 \\
\hline Maret & $\mathrm{BaCl} 2$ & 25 & 25 & 0 \\
\hline April & $\mathrm{BaCl} 2$ & 40 & 35 & 5 \\
\hline Mei & $\mathrm{BaCl} 2$ & 20 & 20 & 0 \\
\hline Juni & $\mathrm{BaCl} 2$ & 30 & 25 & 5 \\
\hline Juli & $\mathrm{BaCl} 2$ & 30 & 25 & 5 \\
\hline Agustus & $\mathrm{BaCl} 2$ & 25 & 25 & 0 \\
\hline September & $\mathrm{BaCl} 2$ & 35 & 20 & 15 \\
\hline Oktober & $\mathrm{BaCl} 2$ & 35 & 30 & 5 \\
\hline Nopember & $\mathrm{BaCl} 2$ & 37 & 34 & 3 \\
\hline Desember & $\mathrm{BaCl} 2$ & 30 & 25 & 5 \\
\hline & Jumlah & 372 & 324 & 48 \\
\hline & ata-rata & 31 & 27 & 4 \\
\hline
\end{tabular}

Diketahui stok awal untuk $\mathrm{BaCl} 2$ tahun 2020 adalah 10 botol dan lead time $=1$. Akan dilakukan sejumlah perhitungan dengan menggunakan metode min-max stock level sebagai berikut:

- $\quad$ Stok akhir tahun $2020=($ Total Pembelian - Total Pemakaian) + Stok Awal Tahun 2020

$=(372-324)+10$

$=58$ Botol

- $\quad$ Safety Stock $=($ Pemakaian Maksimal - Rata-rata Kebutuhan) x Lead Time 
$=(34-31) \times 1$

$=3$ Botol

- $\quad$ Minimum stock $=($ Rata-rata Kebutuhan $\mathrm{x}$ Lead time $)$

+ Safety Stock

$=(31 \times 1)+3$

$=34$ Botol

- $\quad$ Maximum stock $=2 \times$ (Rata-rata Kebutuhan $\mathrm{x}$ Lead time $)+$ Safety Stock

$=2 \times(31 \times 1)+3$

$=65$ Botol

- $\quad$ Tingkat Pemesanan Kembali $(\mathrm{Q})$ = Maksimum Minimum

$=65-34$

$=31$ Botol

Berdasarkan hasil perhitungan di atas, dapat dibuat tabel hasil sebagai berikut:

Tabel 2. Rekapitulasi Perhitungan Metode Min-Max Stock

\begin{tabular}{|c|c|c|c|c|c|}
\hline $\begin{array}{c}\text { Bahan } \\
\text { Baku }\end{array}$ & $\begin{array}{c}\text { Stok } \\
\text { Akhir } \\
2020\end{array}$ & $\begin{array}{c}\text { Safety } \\
\text { Stock }\end{array}$ & $\begin{array}{c}\text { Minimum } \\
\text { Stock }\end{array}$ & $\begin{array}{c}\text { Maximum } \\
\text { Stock }\end{array}$ & $\mathrm{Q}$ \\
\hline $\mathrm{BaCl} 2$ & 58 & 3 & 34 & 65 & 31 \\
\hline
\end{tabular}

Melihat tabel di atas, dapat disimpulkan bahwa stok akhir $\mathrm{BaCl} 2$ tahun 2020 sangat besar jika dibandingkan dengan safety stock yang dihitung dengan menggunakan metode minmax stock. Untuk itu BBPOM Serang perlu mengambil tindakan supaya pada tahun berikutnya tidak terjadi overstock bahan persediaan. Sedangkan jumlah pemesanan kembali (Q) sebanyak 31 botol $\mathrm{BaCl}$, artinya tidak melebihi maximum stock sehingga jumlah yang ditunjukkan Q masih dalam keadaan normal. Seperti ini data yang ditampilkan oleh metode min-max stock level untuk membantu para manajemen suatu perusahaan atau organisasi dalam menganalisa persediaan barang yang ada di organisasi mereka.

\section{HASIL DAN PEMBAHASAN}

Pada pembahasan ini, selain dari proses CRUD (Creat-ReadUpdate-Delete) yang ada pada setiap user interface baik untuk entri data master maupun data transaksi, penulis akan menjelaskan empat proses penting yang akan dikembangkan di dalam sistem aplikasi. Adapun keempat proses tersebut adalah:

1. Proses penambahan stok barang di gudang (stock in) melalui proses entri nama dan jumlah barang yang masuk ke gudang setelah dilakukan pengiriman oleh supplier.

2. Proses pengurangan stok barang di gudang (stock out) melalui proses entri nama dan jumlah barang sesuai dengan request yang dilakukan oleh user atau pegawai internal BBPOM Serang.

3. Proses closing dilakukan untuk menentukan akhir setiap barang pada akhir bulan berjalan. Stok akhir tersebut menjadi stok awal setiap barang persediaan pada bulan berikutnya. Proses closing dilakukan pada setiap akhir bulan pada bulan berjalan.
4. Proses perhitungan variabel yang ada pada metode min-max stock level yaitu safety stock, minimum inventory, maximum inventory dan reorder point setiap barang.

Berdasarkan proses closing dan proses perhitungan variabel dengan metode min-max stock level, dapat dihasilkan sebuah tabel yang mempunyai kolom data berupa: stok akhir, safety stock, minimum stock, maximum stock dan reorder quantity. Berdasarkan hasil perhitungan itu, maka Pejabat Pembuat Komitmen (PPK) atau Kepala Balai dapat dengan mudah dalam melakukan analisa pengadaan persedian untuk tahun berikutnya. Jadi angka yang dihasilkan berdasarkan perhitungan metode min-max stock level dapat dijadikan sebagai data pendukung dalam memutuskan atau menentukan berapa jumlah stok minimum dan maksimum suatu barang persediaan untuk kurun waktu tertentu. Sehingga jumlah stok tidak terlalu banyak atau menumpuk di gudang dan tidak terlalu sedikit bahkan minus sehingga dapat mengganggu kinerja dari BBPOM Serang.

\section{A. Blok Algoritma Proses Pada Program}

1) Proses Penambahan Jumlah Barang (Stock In)

- Proses penambahan terjadi saat admin melakukan entri data barang yang masuk ke gudang setelah melalui proses pembelian atau ada pengembalian barang dari user karena ada sisa pemakaian.

- Jumlah yang dientri akan menambah jumlah qty_in pada tabel master barang.

- function stock_in ()

\{\#cari jumlah qty_in pada master barang\#

\$jml_in = (SELECT qty_in FROM barang

WHERE id_barang = \$id_barang)

\#jika barang masuk dari supplier maka catat

jumlah barang yang tampil pada screen\#

\$curr_qty_supplier = \$screen_qty_supplier

\#catat jumlah barang yang dientri\#

\$entri_qty_supplier = \$entri_qty_supplier

\#hitung qty_in pada master barang\#

\$total_in_supplier $=($ \$jml_in -

\$curr_qty_supplier) + \$entri_qty_supplier

\#jika barang masuk dari user (sisa pemakaian)

maka catat jumlah barang yang tampil pada

screen\#

\$curr_qty_user= \$screen_qty_user

\#catat jumlah barang yang dientri\#

\$entri_qty_user = \$entri_qty_user

\#hitung qty_in pada master barang\#

\$total_in_user $=($ \$jml_in - \$curr_qty_user $)+$

\$entri_qty_user

\#update qty_in pada master barang\#

UPDATE barang SET qty_in = \$total_in_user WHERE id_barang $=$ \$id_barang $\}$

\section{2) Proses Pengurangan Jumlah Barang (Stock Out)}


- Proses terjadi saat admin entri barang keluar dari gudang sesuai permintaan user

- Jumlah yang dientri akan menambah jumlah barang keluar (qty_out) pada master barang.

- function stock_out ()

\{\#cari jumlah qty_out pada master barang\#

\$jml_out $=($ SELECT qty_out FROM barang

WHERE id_barang = id_barang)

\#catat jumlah barang yang tampil pada screen\#

\$curr_qty = \$screen_qty

\#catat jumlah barang yang dientri\#

\$entri_qty = \$entri_qty

\#hitung qty_out pada master barang\#

\$total_out $=($ \$jml_out + \$curr_qty $)$ - \$entri_qty

\#update qty_out pada master barang\#

UPDATE barang SET qty_out = \$total_out WHERE id_barang $=$ \$id_barang $\}$

\section{3) Proses Closing}

- Proses dilakukan setiap akhir bulan dengan parameter input tanggal closing.

- Hasil proses closing per periode disimpan pada tbl_closing, sehingga histori akumulasi barang masuk, barang keluar dan total stok per barang per periode dapat ditelusuri.

- Hasil proses closing menjadi stok akhir setiap item barang pada bulan berjalan. Jumlah ini juga menjadi stok awal pada periode bulan berikutnya.

- Lakukan update stok awal pada tabel master barang

- Function closing ()

\{\#insert semua data pada barang ke tbl_closing

INSERT INTO tbl_closing (id_barang, kode_barang) SELECT id_barang, kode_barang FROM barang

\#lakukan looping pada tbl_closing untuk mencari total barang masuk gudang dari tabel barang_masuk_rinci, total barang keluar gudang dari barang_keluar_rinci serta stok awal pada barang selama periode satu bulan\# \$barang = SELECT id_barang, kode_barang FROM tbl_closing

\$result=mysqli_query $($ barang $)$

if (mysqli_num_rows $($ \$result $)>0$ )

$\{$ \$stock_in = SELECT SUM(jml_masuk) FROM barang_masuk_rinci WHERE id_barang $=$ \$id_barang AND periode $=\$$ periode

\$stock_out = SELECT SUM(jml_keluar) FROM

tbl_barang_keluar_rinci WHERE id_barang $=\$$ id_barang AND periode $=$ \$periode

\$begin_stock = SELECT stok_awal FROM barang where id_barang $=$ \$id_barang

\$closing_stock $=$ \$begin_stock + \$stock_in \$stock_out

\author{
\#update tbl_closing \\ UPDATE tbl_closing SET begin_stock = \\ \$begin_stock, stock_in = \$stock_in, stock_out = \\ \$stock_out, total_stock $=\$$ closing_stock \\ WHERE id_barang = \$id_barang AND periode \\ $=\$$ periode
}

\#jika terjadi ketidaksesuaian stok akhir di tabel barang dan tabel tbl_closing, lakukan pemeriksaan dan penyesuaian\#

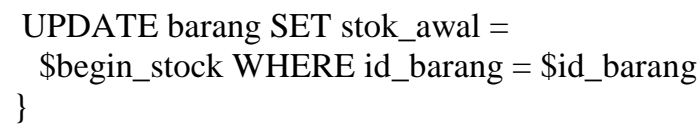

4) Proses Min-Max Stock Level

- Buat temporary table untuk menyimpan hasil perhitungan dengan metode min-max stock level, misalnya tbl_rekap

- Hitung rata-rata kebutuhan setiap item barang per tahun dari tbl_barang_keluar_rinci

- Cari jumlah pemakaian terbanyak dalam satu tahun dari tbl_barang_keluar_rinci

- Lakukan perhitungan terhadap variabel safety stock, minimum stock, maximum stock dan reorder point sesuai dengan metode min-max stock.

- Function min_max_stock ()

\{\#cari rata-rata kebutuhan

\$rata = SELECT SUM(jml_keluar)/12 FROM

tbl_barang_keluar_rinci WHERE id_barang =

\$id_barang AND periode $=$ \$periode

\#cari jumlah pemakaian terbanyak dalam setahun\#

\$terbanyak = SELECT MAX $($ SUM $($ jml_pakai $))$

FROM tbl_barang_keluar_rinci WHERE

id_barang $=$ \$id_barang AND periode $=$ \$periode

\#cari stok akhir tahun untuk setiap barang persediaan\#

\$stok_akhir = SELECT begin_stock FROM tbl_closing WHERE id_barang = \$id_barang AND periode $=\$$ periode

\$leadtime $=1$

\$safety_stock $=($ \$terbanyak - \$rata $) *$ \$leadtime

\$min_stock $=($ rata $*$ leadtime $)+$ \$safety_stock

\$max_stock $=2 *($ \$rata $*$ \$leadtime $)+$ \$safety_stock

\$Q = \$max_stock - \$min_stock

\#insert ke tbl_rekap hasil perhitungan metode min_max stock\#

INSERT INTO tbl_rekap (id_barang, stok_akhir, safety_stock, min_stock, max_stock, Q) VALUES 
(\$id_barang, \$stok_akhir, \$safety_stock, min_stock, max_stock, \$Q) \}

\section{B. Pemodelan Proses Bisnis}

Pemodelan proses bisnis untuk Sistem Informasi Persediaan Barang Pada BBPOM Serang dilakukan dengan menggunakan Data Flow Diagram (DFD). Diagram konteks di bawah ini menjelaskan bagaimana hubungan antara entitas luar dengan sistem aplikasi secara keseluruhan.
Gambar 2. Diagram Konteks SI Persediaan

Gambar 3 merupakan diagram yang memperlihatkan proses untuk semua modul yang ada di dalam sistem (overview) yaitu modul untuk entri data master, data transaksi dan proses untuk menghasilkan berbagai jenis laporan.
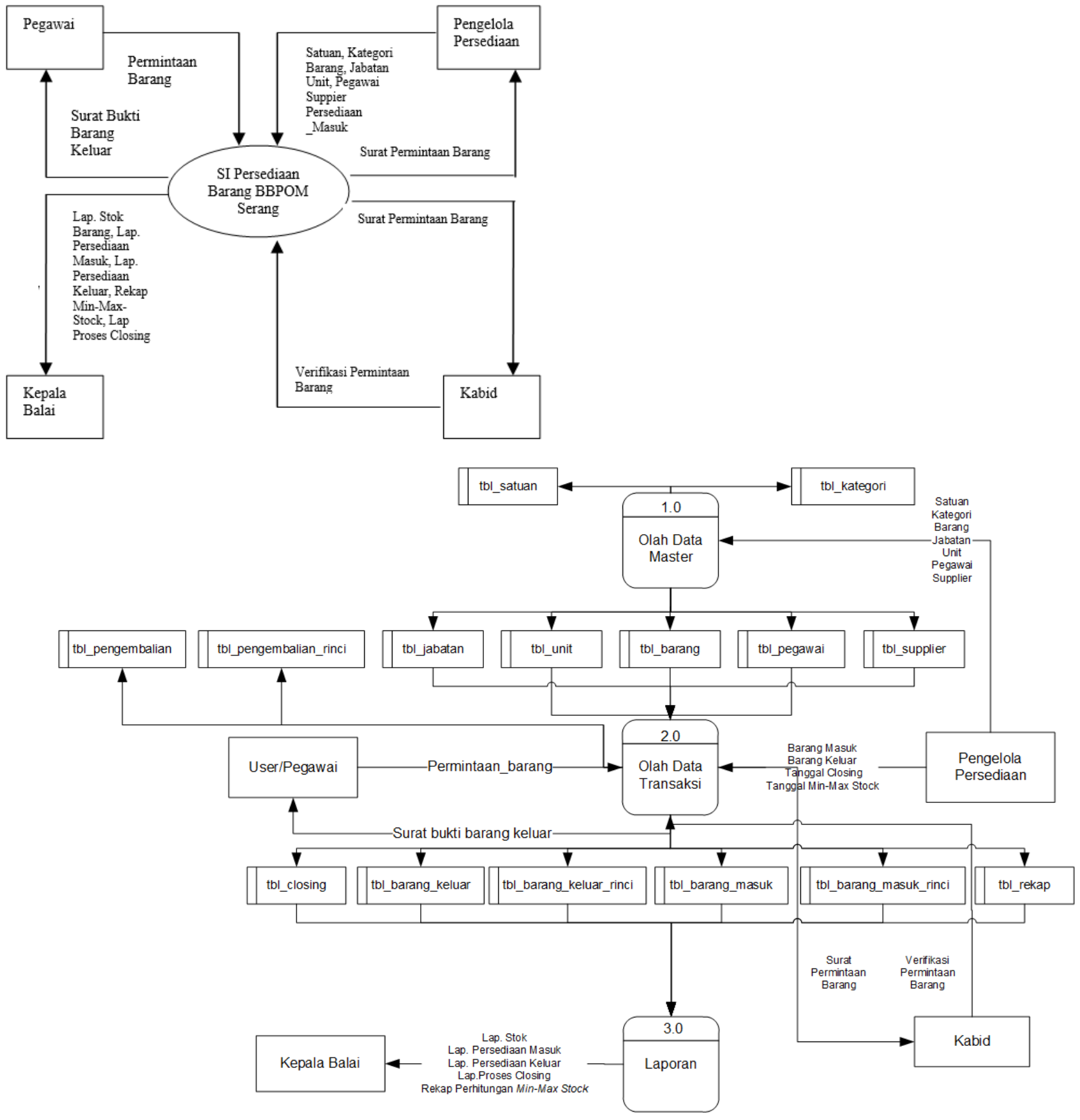


\section{Gambar 3. Diagram Overview Sistem}

Penulis akan menjelaskan lebih lanjut untuk diagram proses Sedangkan proses CRUD (Creat, Read, Update, Delete) untuk 2.0 Olah Data Transaksi pada Gambar 4.a dan Gambar 4.b. proses 1.0 Olah Data Master tidak dijelaskan pada artikel ini.

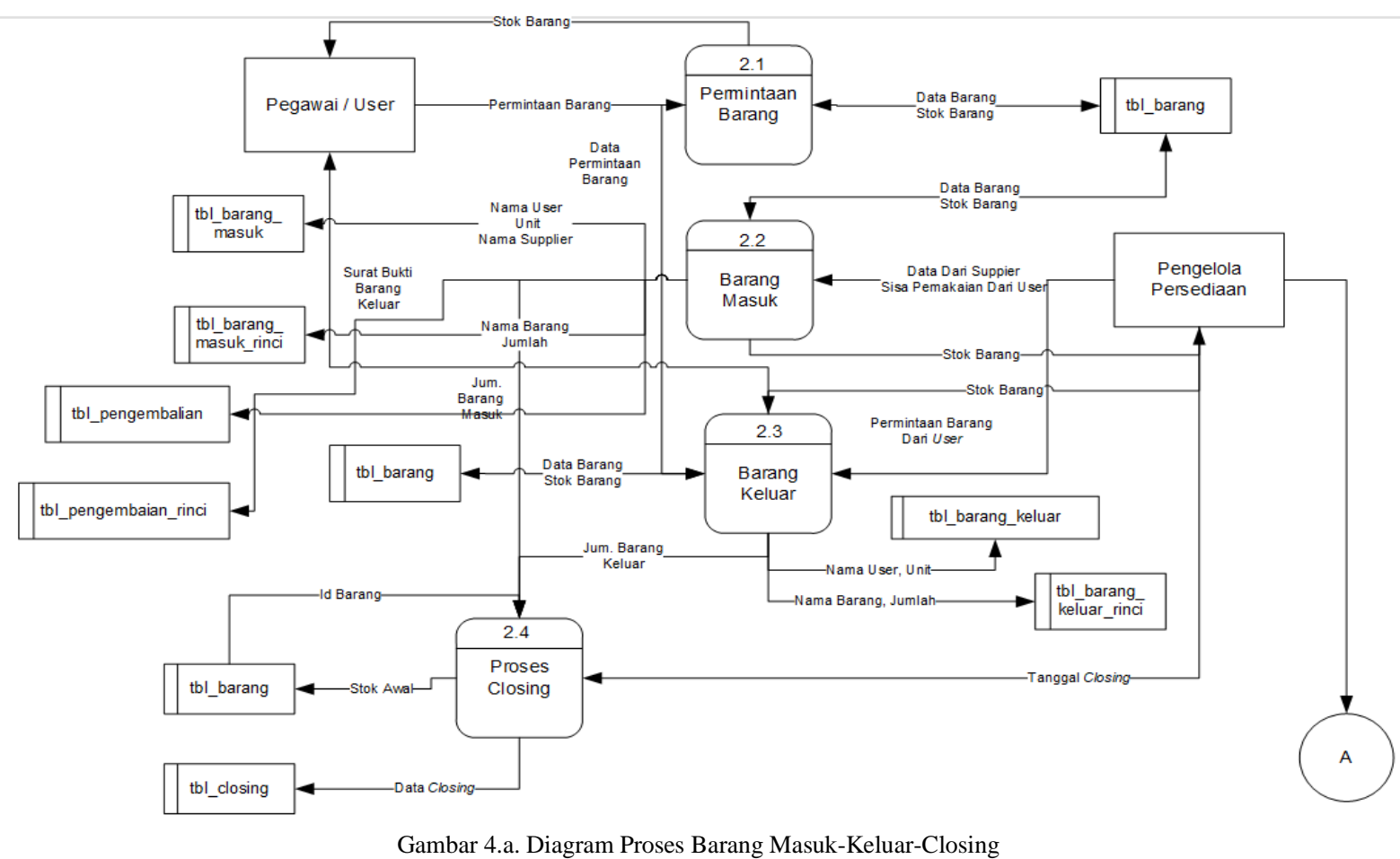

Diagram pada Gambar 4.a memperlihatkan bagaimana alur proses mulai dari user atau pegawai melakukan entri permintaan barang, user dapat melihat stok pada sistem, pengelola persediaan melakukan entri barang masuk dari supplier maupun sisa pemakaian dari user serta entri barang keluar sesuai permintaan user. 


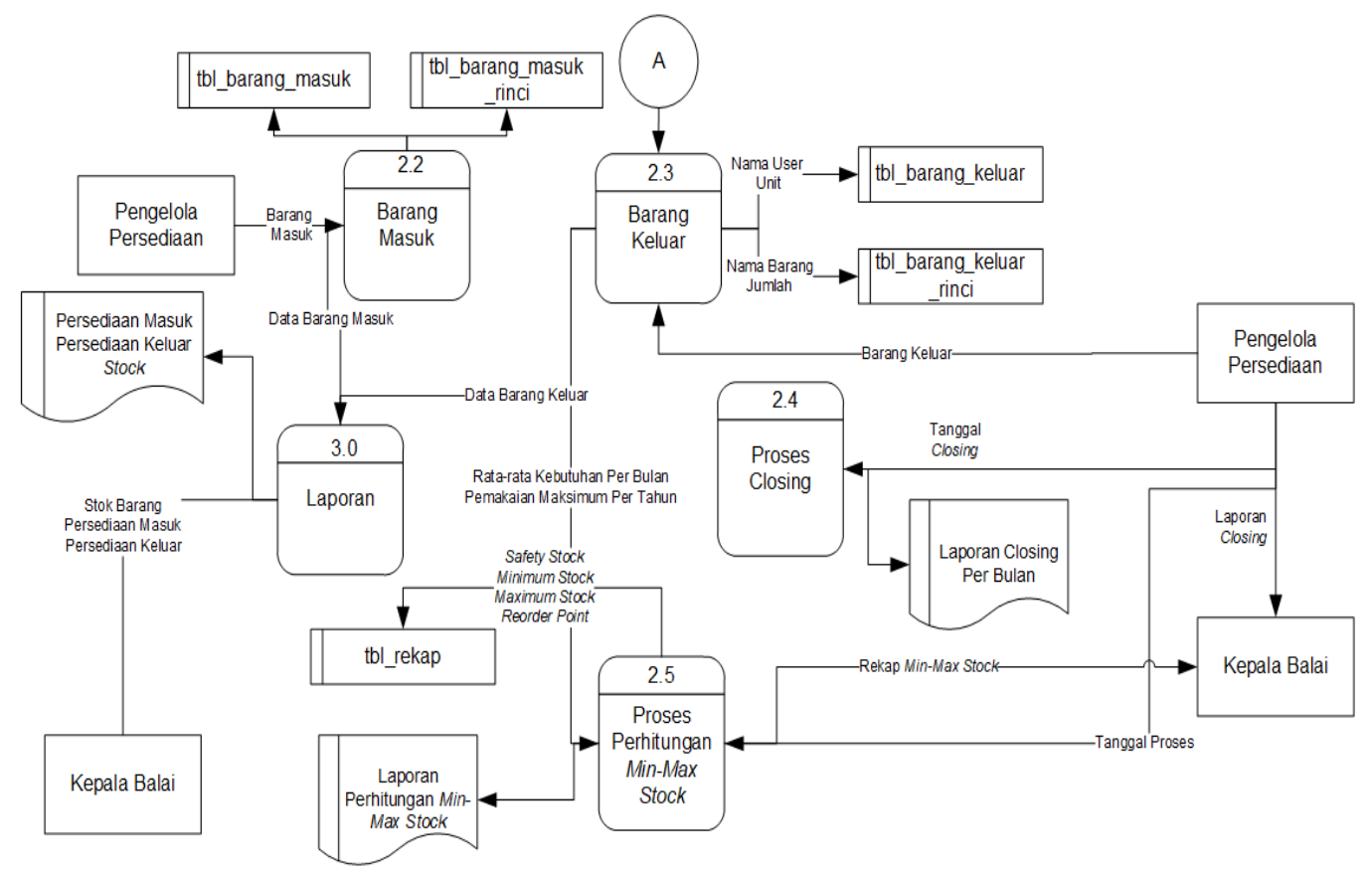

Gambar 4.b. Diagram Proses Perhitungan Min-Max Stock dan Laporan

Diagram pada Gambar 4.b memperlihatkan alur proses pembuatan laporan dan proses perhitungan dengan menggunakan metode min-max stock level untuk menghasilkan data bagi Kepala Balai dalam menganalisa persediaan di gudang sehingga persediaan tetap ada saat dibutuhkkan tetapi tidak over stock.

\section{Pemodelan Basis Data}

Gambar 5. memperlihatkan hubungan antara entitas atau table yang ada pada sistem database.

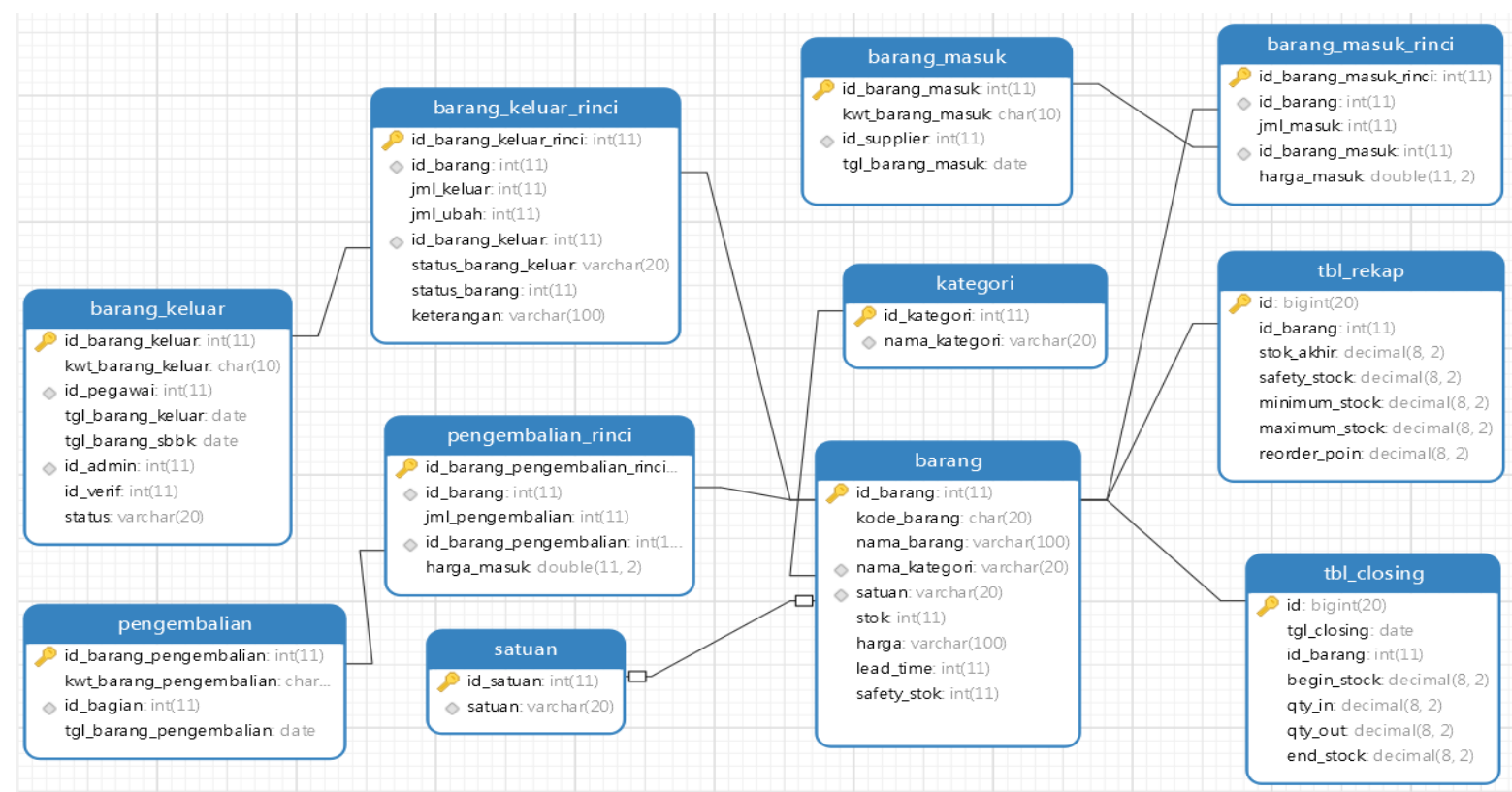

Gambar 5. Entity Relationship Diagram

\section{Implementation}


Pada pembahasan implementasi ini, penulis hanya menu Transaksi dan beberapa bentuk laporan. menampilkan beberapa screenshoot saja yaitu screen dari

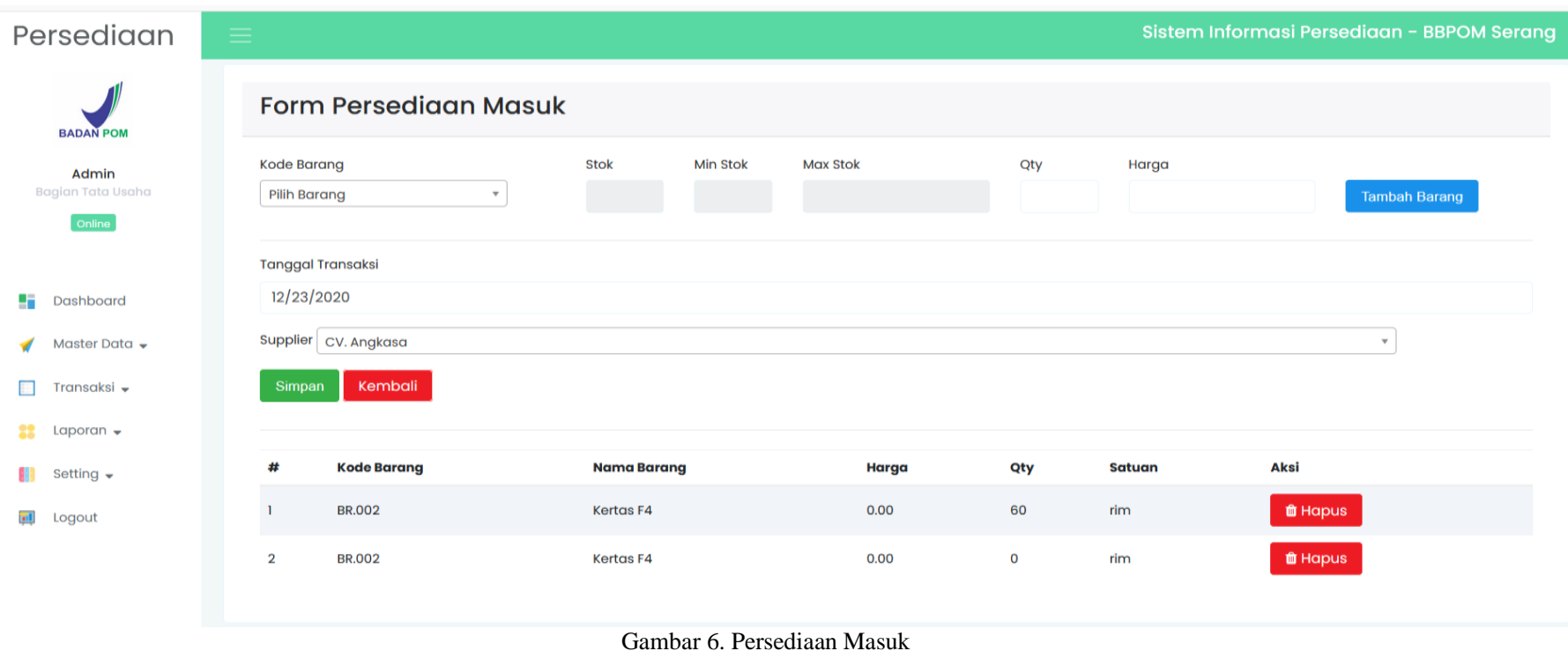

Persediaan
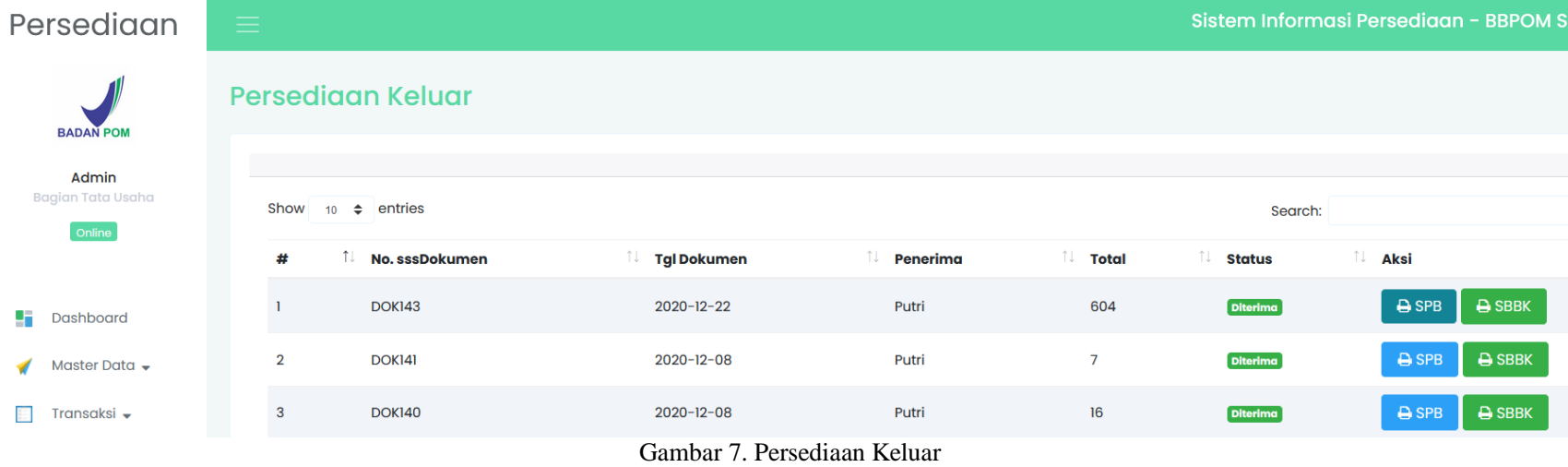

Persediaan
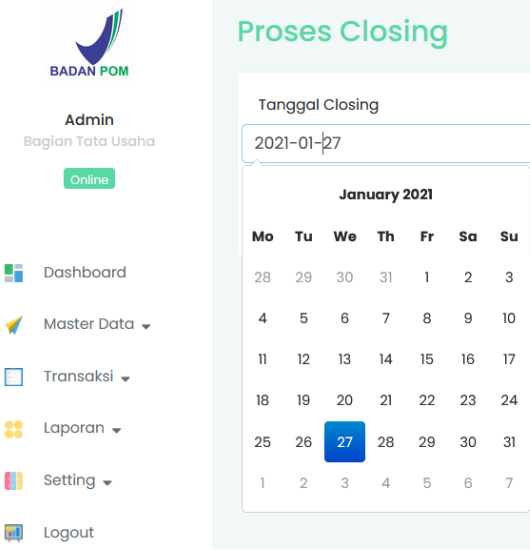


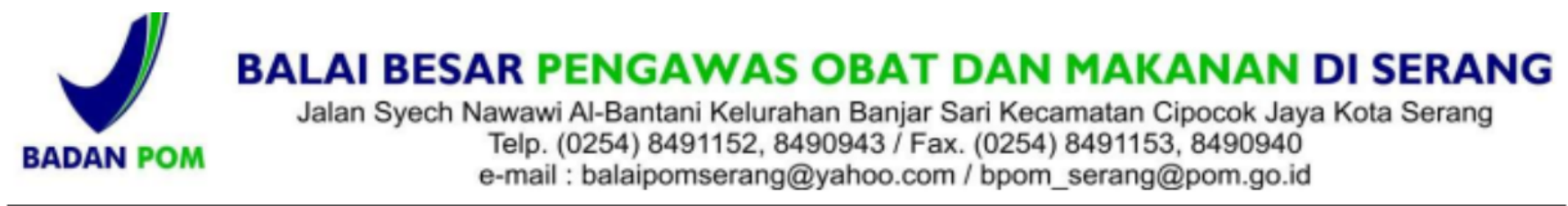

Hasil Closing

Periode: 27 Januari 2021. Jam: 11:26

\begin{tabular}{|c|c|c|c|c|c|c|c|}
\hline No & Kode Barang & Nama Barang & Satuan & Begin Stok & Qty In & Qty Out & Ending Stock \\
\hline 1 & CR.002 & Brilliat Green (Hijau Berlian) & Botol@1000 gr & 10.00 & 15.00 & 19.00 & 6.00 \\
\hline 2 & CR.003 & Boiling Chips / Batu Didih & Botol@100 gr & 15.00 & 25.00 & 33.00 & 7.00 \\
\hline 3 & CR.004 & Boric Acid (Asam Borat) & Botol@1000 gr & 7.00 & 20.00 & 24.00 & 3.00 \\
\hline 4 & CR.010 & Alkohol $96 \%$ & Drigen@20 Itr & 5.00 & 10.00 & 12.00 & 3.00 \\
\hline 6 & CR.019 & Asam Folat & $200 \mathrm{mg} / \mathrm{vial}$ & 8.00 & 15.00 & 18.00 & 5.00 \\
\hline 7 & CR.020 & Betametason Valerat & $200 \mathrm{mg} / \mathrm{vial}$ & 12.00 & 18.00 & 22.00 & 8.00 \\
\hline 8 & CR.021 & Adhesive Label No 99 & Pack & 10.00 & 17.00 & 20.00 & 7.00 \\
\hline 9 & CR.022 & Bussines File & Pcs & 10.00 & 25.00 & 28.00 & 7.00 \\
\hline 10 & CR.023 & Apar 2 kg (CO2) & Buah & 5.00 & 2.00 & 5.00 & 2.00 \\
\hline
\end{tabular}

Gambar 9. Hasil Proses Closing

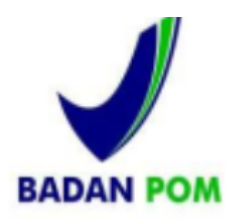

BALAI BESAR PENGAWAS OBAT DAN MAKANAN DI SERANG

Jalan Syech Nawawi Al-Bantani Kelurahan Banjar Sari Kecamatan Cipocok Jaya Kota Serang

Telp. (0254) 8491152, 8490943 / Fax. (0254) 8491153, 8490940

e-mail : balaipomserang@yahoo.com / bpom_serang@pom.go.id

Hasil Metode Min-Max Stock Level

Periode: 27 Januari 2021. Jam: 11:28

\begin{tabular}{|l|l|l|r|r|r|r|}
\hline No & Kode Barang & Nama Barang & Ending Stock & Safety Stock & Minimum Stock & Maximum Stock \\
\hline 1 & CR.002 & Brilliat Green (Hijau Berlian) & 6.00 & 3.00 & 5.00 & 15.00 \\
\hline 2 & CR.003 & Boiling Chips / Batu Didih & 7.00 & 3.00 & 10.00 \\
\hline 3 & CR.004 & Boric Acid (Asam Borat) & 3.00 & 2.00 & 18.00 & 3.00 \\
\hline
\end{tabular}

Gambar 10. Hasil Proses Min-Max Stock

\section{KESIMPULAN}

Pengembangan Aplikasi Sistem Informasi Persediaan berbasis web pada BBPOM Serang dapat mempercepat proses pembuatan laporan dan stok dapat dilihat secara realtime. Metode Min-Max Stock dapat membantu Kepala Balai dalam melakukan analisa pengadaan persediaan di BBPOM Serang.

\section{REFERENSI}

[1] Fadhilah, S. N., Andreas, \& Zahedi. 2008. Metode Pengendalian Persediaan Bahan Baku Crude Coconut Oil Yang Optimal Pada PT. PSE. INESEA, Vol. 9 No.2 Universitas Bina Nusantara.

[2] Indrajit, R., \& Djokopranoto. 2003. Konsep Manajemen Supply Chain: Strategi Mengelola Manajemen Rantai
Pasokan Bagi Perusahaan Modern di Indonesia.Jakarta: PT Gramedia Widiasaranan Indonesia

[3] Herjanto, Eddy. 1999. Manajemen Produksi dan Operasi. Edisi Kedua. Jakarta: Grasindo.

[4] Sommerville, I. 2011. Software Engineering $9^{\text {th }}$ Edition. United States of America: Addison-Wesley.

[5] Triyono, G. 2011. Pertimbangan Melakukan Denormalisasi Pada Model Basis Data Relasi dalam Jurnal Telematika Mkom, Vol.3 No,2 (hlm. 19).

[6] Nugroho, Adi. 2005. Rational Rose untuk Pemodelan Berorientasi Objek. Bandung: Informatika.

[7] Online.visual-paradigm.com. What is System Context Diagram? Diakses pada 14 Januari 2021, https://online.visual-paradigm.com/knowledge/systemcontext-diagram/what-is-system-context-diagram. 
[8] Kristanto, Andri, 2008, Perancangan Sistem Informasi dan Aplikasinya, edisi revisi, Yogyakarta: Gava Media.

[9] Kendall, Kenneth E. Dan Kendall, Julie E., 2003, Analisis dan Perancangan Sistem Edisi Kelima Jilid 1 dan Jilid 2, Jakarta: Prenhallindo.

[10] Murti, Karima Batennia. 2019. Penentuan Stock Minimal-Maksimal dan Pola Perancanaan Produksi Pada Seksi Painting Plastik di PT. ABC. ISSN: 25796429.

[11] C. Yedida, and M. Ulkhaq. 2017. Perencanaan Kebutuhan Persediaan Material Bahan Baku Pada CV Endhigra Prima dengan Metode Min-Max. Industrial Engineering Online Journal, vol. 6, no. 1, Jan. 2017. 